\title{
Exploring Dysphasia Learners' Vocabulary Acquisition through the Cognitive Theory of Multimedia Learning: An Experimental Study
}

\author{
https://doi.org/10.3991/ijet.v16i12.22173 \\ Aravind B R( $\left.{ }^{\bowtie}\right)$, Rajasekaran V \\ Vellore Institute of Technology, Chennai, India \\ aravind.aburegmail.com
}

\begin{abstract}
Purpose of the study: The present study was conducted to investigate the impact of the Cognitive Theory of Multimedia Learning for students with dysphasia in learning disabilities. Another aim was to find out the acquisition of vocabulary toward News in levels lesson - Robinson Crusoe for Students of English. Twenty-four students with dysphasia in learning disabilities have participated in the study. The sample population was exposed to a similar handing environment for the research though they had various backgrounds. All the instructions, experiments, teaching-learning activities were provided in the special education resource room.

Methodology: The Experimental Research Design was employed in the study. Pre-test, post-test, retention test, and Vocabulary Knowledge Scale questionnaire were administrated to collect the required data from both the control and experimental groups to study the impact of the multimedia and nonmultimedia instructional methods.

Major findings: The research findings revealed that the multimedia instructional method of teaching outperformed the non-multimedia instructional group. The retention test results and the Vocabulary Knowledge Scale questionnaire reaffirmed that students with dysphasia have motivated and store the new information in their long-term memory. They could retain most of the vocabulary when the multimedia instructional method was integrated into the teachinglearning process. All the test result scores were analyzed using the SPSS software package. A paired test value comparison was used to compare the results for both the control and experimental groups.
\end{abstract}

Keywords - Dysphasia, Cognitive Theory of Multimedia Learning, Vocabulary Knowledge Scale, Acquisition, Instructional learning

\section{$1 \quad$ Introduction}

Vocabulary knowledge plays a sufficient role in language acquisition. Vocabulary is the foundation to develop listening, speaking, reading, and writing skills [1]. Accordingly, vocabulary is the fundamental element of the language undoubtedly. It is also believed that vocabulary is the building block of language learning; simultaneously, students with learning disabilities find it challenging and difficult to build those 
blocks than non-disabled students. Learning disabled students is reported to demonstrate deficits in reading comprehension and vocabulary acquisition [2]. Students with learning disabilities need explicit instruction because they may have trouble with word-learning strategies [3]. Researchers, special educators, and experts in the field strongly believe students with learning disabilities need to practice vocabulary. When students engage in the learning process, they pay attention, concentrate on educational involvement, and gushed about accomplishing the learning objective. Lack or absence of exposure to explicit vocabulary practices will result in limited usability of words. If students are to become knowledgeable and fluent readers, they must understand the meaning of concepts and the words that describe those ideas.

Children must grasp the semantic cueing system and conventions in addition to their knowledge of the graphophonic cueing system and conventions. Students must consider the vocabulary that helps them grasp what they are reading and the techniques needed to find the context during the reading process. Vocabulary cannot be left to chance; it must be created, expanded, and taught. Developing and expanding special learners' vocabulary is a dynamic task that involves multiple exposures to vocabulary and their interpretations. They must always be instructed to use a variety of word-learning approaches when they encounter unfamiliar words in their reading. Successful vocabulary teaching is possible when students are introduced to words in several contexts. The words should be learned within the framework of a unit. The role of the teacher is to assist students in triggering previous knowledge when acquiring new words. Learners have to study the relationship between new words and established words. Students are advised to use meaning cues and reference tools such as dictionaries to improve their word knowledge. Importantly, students must be encouraged to engage with the words to process learning profoundly [4]. This research paper aims to bridge those gaps and explore the vocabulary knowledge of dysphasia students. Cognitive Theory of Multimedia Learning and its instructional approaches are facilitated to study and investigate the impact of the outcome from the vocabulary instructions.

\section{Review of Literature}

This section reviews some of the relevant previous researches which are closely related to the current study. The following reviews shed light on learning disabilities students' language skills, teaching vocabulary for dysphasia students, multimedia tools and approaches to teaching special learners, and its associative theories. The research was carried out to improve learning disabilities students' sight word vocabulary through racetracks and flashcards [5]. The research outcome indicated that reading racetracks are an effective method in increasing learning disabilities students' vocabulary. It has been discussed that the computer can be used to enhance reading skills to children but not substitute the educator [6]. A study on the use of computerassisted teaching and language programs was conducted. Creating a semantic network dictionary with a massive empirical database would help dysphasia children develop speech therapy and maintain semantic structures [7]. A longitudinal follow-up study of 300 children with developmental dysphasia was reported. The study investigated a battery of tests like spoken, phonological processing, and audiometric procedures. 
The result showed that central auditory perception disorder confirmed the developmental dysphasia for those children, which ends with difficulties in phonemes and similar words [8].

The parental involvement practices for children with dysphasia into inclusive classes in a primary school in the research article was explored [9]. The study results showed that practices were interdependent because of individual factors and environmental situations. Integrating YouTube videos during reading activities on vocabulary development using multimedia learning's cognitive theory was investigated. The findings of the study revealed that learners facilitated with YouTube have statistically significant efforts on vocabulary acquisition [10]. The dual-coding and cognitive theory of multimedia media as the basis for developing vocabulary learning and acquisition [11]. The research article has explored tools that actively engage learners, particularly short-term and long-term vocabulary recall and development, to understand word knowledge effectively.

The virtual laboratory model helped special educational needs students for online courses. According to the model, the virtual laboratory was facilitated with several conditions. Inclusive education made special learners minimize the number of actions performed by them. The virtual laboratory was implemented especially for students with hearing and vision impairment and musculoskeletal disorders. The color consistency adjusts contrast and brightness for visual impairments and a separate tool to simplify operation for musculoskeletal disorders. Recommendations for adapting the virtual laboratory model for learners with other special educational needs were mentioned [12]. The technological modalities [13] would encourage special learners to study new online courses. In an online learning environment, learners are given unique platforms to communicate individually and collaboratively with teachers. [14]. Modern curriculum design and large-scale online classes have significantly transformed the mode and usability of learning and teaching; they have also affected academic study and higher education [15].

\section{$3 \quad$ Vocabulary and Learning Disabilities in Dysphasia}

Individuals with Disabilities Education Act (IDEA) of 2004 reported that disabilities must be taught in the Least Restrictive Environment (LRE). The act wishes that learners with disabilities can be educated and non-disabled learners to the highest range feasible. This affords learners with disabilities access to general education curricula and other programs accessible to their non-disabled learners. Students with learning disabilities generally have inadequate vocabulary understanding and have difficulty learning academic vocabulary as a language-based activity [16]. Inadequate contextual knowledge, deprived study skills, cultural or language differences, and the lack of ability to pay attention are some reasons that have an emotional impact on learning. It also suggested that children with learning disabilities lack the metacognitive skills and learning strategies to overcome these problems, making their learning proficiencies challenging or perplexing [17]. Few learners with learning disabilities may be incompetent to repeat important or central ideas. This may create vocabulary acquisition a problematic one [18]. 
These learning disabilities occur, particularly in students with dysphasia. Dysphasia is a communication disorder that results in difficulties to understand, language development, words, and speech. Hence, verbal communication is inhibited for children with dysphasia. Dysphasia is of three types, categorically Broca's dysphasia, Wernicke's dysphasia, and Anomic dysphasia. Each dysphasia has different learning disabilities in specific. Dysphasia is a disabling disorder with a wide range of severity and a multitude of causes. The disorder may range from an occasional failure to locate the appropriate word to serious dysphasia with sensitive and verbal elements. There are two forms of dysphasia: fluent and non-fluent.

Non-fluent dysphasia is associated with more anterior cerebral hemisphere lesions, while fluent dysphasia is identified with more posterior cerebral hemisphere lesions. The testing aims to get an understanding of the patients' cognitive and expressive abilities. The ability to read words and letters and name them or read them but not name them is measured. Responses to various verbal interactions, ranging from basic directives to nuanced ones, are examined [19]. In general, students with dysphasia have language-based learning disorders like inability to understand the meaning of words, inability to retell a story, and inability to produce spoken language. To overcome such language-based difficulties, learners with dysphasia have to enhance their vocabulary knowledge. Many scholars have observed the problems these children come across. Their vocabulary is often limited, their language is less mature than other children of their age, and they have difficulties with reading comprehension and understanding language sensitivities [20-22]. Hence, multiple repetitions and student engagement are essential to learners' vocabulary acquisition and understanding of the text.

\section{$4 \quad$ Research Objectives}

- To determine whether News in Levels lesson improves vocabulary development of the learning disability in dysphasia students.

- To know whether the cognitive theory of multimedia learning positively contributes to dysphasia students' vocabulary mastery.

- To describe the learning situation when the multimedia learning approach is applied during the teaching process for learning disability students.

\section{$5 \quad$ Research Questions}

- To what extent does teaching the vocabulary through News in Levels lesson result in higher acquisition for learning disability students?

- How do learners who received News in Levels lesson teaching perform on vocabulary acquisition?

- Are dysphasia students satisfied with the use of the multimedia instructional learning approach for vocabulary learning?

- Will the method of instruction on vocabulary increase the learning atmosphere and engagement for learning disability students? 


\section{Significance of the Study}

The present study is expected to add to the existing literature in the field. The findings of this study can be beneficial to various groups of people. Dysphasia students, both in and outside the classroom, will be able to apply multimedia learning for lifelong learning. Special education teachers can instruct and employ the theory and approaches that facilitate dysphasia students' vocabulary development. This investigation's findings may be an information base for further research in learning disability or related areas. Implications for the design and teaching of pedagogical curricula can be formulated.

\section{Theoretical Framework}

Richard Mayer's Cognitive Theory of Multimedia Learning was adopted for the theoretical foundation to study students with dysphasia for vocabulary knowledge. The cognitive theory of multimedia learning states that "people learn more deeply from words and pictures than from words alone" [23]. The theory strongly demands instructional media to explore the human mind to channel the learning and add words to the picture. The multimedia principle must be appropriately channelized with limited capacity to achieve an effective way of multimedia learning. Multimedia Instructional settings are generally known to have an immense capacity for changing the way people learn. Learners in multimedia learning settings are introduced to content in both textual and pictorial formats. While verbal modes of presentation have long dominated curriculum, there is positive evidence that incorporating visual forms of presentation can increase student comprehension [24]. The cognitive theory of multimedia learning is an active process of selecting words, selecting images, organizing words, organizing images, and integrating verbal and pictorial models based upon prior knowledge. The use of multimedia and technology makes it possible for students to explore the content easily.

\section{Samples and Sample Size}

The study consists of 24 6th-grade students attending a special education school in an urban district located in Chennai, Tamilnadu participated in this research study. Those participants were already studying in the special school as identified learning disables by school district personnel using state eligibility standards and were receiving training in the special education school curriculum. Demographic details of participants' background and the length of time learning English were gathered from the samples' responses. To determine and diagnose the participants' initial level, the online test was conducted before the study began. The data indicated that the participants undergo dysphasia in learning, especially they find difficulty in vocabulary.

Additionally, a special education teacher was assisted in the study to provide technical instruction to the participants. The sample population was exposed to a similar 
handling environment for the research though they had various backgrounds. All the instructions, experiments, teaching-learning activities were provided in the special education resource room.

\section{$9 \quad$ Instructional Material}

Based on the study's theory and approach, News in levels lesson - Robinson Crusoe for students of English was adopted for dysphasia students to enhance their vocabulary. News in levels started in March 2011 to help students to learn and understand English better. News in levels has a unique method for choosing easy words for Level 1, Level 2, and Level 3 to learn English naturally and quickly. Every chapter of the lesson from Robinson Crusoe for students of English has a set of vocabulary corners separately for all three levels, like Level 1, Level 2, and Level 3, respectively. The number of words increases as the level increases. The present study employs Level 1 for dysphasia students from the lesson Robinson Crusoe for students of English. The participants needed to perform well, recognising and using the learned vocabulary from the instructional material.

\section{Procedure}

\subsection{Research design}

The research was carried out in an experimental design with 24 and divided equally into two experimental and control groups. The 24 dysphasia students were randomly divided into two groups of 12, and they were given two instructional learning methods in the special education resource room. These groups were purposefully separated for the experiment purpose to study the multimedia instructional and non-multimedia instructional accomplishments for dysphasia students. At the end of the study, observations and tests were made to assess the approach's learning outcome. Retention test and Vocabulary Knowledge Scale questionnaire were held to evaluate and test the study's long-term effects [25]. Instructional time was precisely the same for both groups. There were ten sessions, each for the entire study, to both the groups. The first session is dedicated to diagnosing, and the last session is to review and recapitulate the previously taught lessons. On the whole, 80 words from News in levels lessonRobinson Crusoe for students of English were discussed during the study period for students with dysphasia.

\subsection{Controlled group}

In this group, the researcher introduced the News in levels text lesson - Robinson Crusoe for students of English, which was on focus during each session. The lesson consisted of a vocabulary corner, and each word was pronounced, and students were instructed to repeat. Subsequently, all the remaining words during the sessions were 
taught. Few words were taught with teaching aids like flashcards, real objects available in the special education resource room except multimedia tools.

\subsection{Experimental group}

This group was also introduced to the same News in levels multimedia lesson Robinson Crusoe for students of English by the researcher. But here, for the experimental group, the lesson was taught with multimedia instructions. News in levels, Robinson Crusoe for students of English was played to the participants' group. These words were explicitly taught with the help of a multimedia instructional approach. The audio and video were played frequently to know each word's pronunciation, spelling, and meaning. Other than multimedia presentations, no other teaching aids were used for the experimental group.

\subsection{Test design}

The pre-test was held before the study with closed-ended questions to test the previous knowledge of the participants. The post-test was held immediately after the ten sessions to test the teaching process's acquired knowledge. The tests contained individual scores - the marks calculated by participants' usability of the learned words from the instructional methods. The retention test was held one month after the ten research sessions. The follow-up test results would help the researcher get the research's reliability, and the level of retrieval for dysphasia students can also be studied. Additionally, the Vocabulary Knowledge Scale questionnaire was circulated one week after the retention test to measure the vocabulary knowledge level of those dysphasia students after the instructional methods. The existing questionnaire responses would add more accountability to the research.

\section{Results}

Pre-test, post-test, retention test, and Vocabulary Knowledge Scale questionnaire test results were analyzed using the SPSS software package. A paired test value comparison was used to compare all the control and experimental groups' tests. Each test's descriptive data for the two groups are presented in Table 1, Table 2, Table 3, and Table 4, respectively.

Table 1. Statistical data of pre-test results

\begin{tabular}{|l|c|c|}
\hline \multicolumn{1}{|c|}{ Pre-test Results } & Mean & Standard Deviation \\
\hline Control Group & 2.1000 & 2.46982 \\
\hline Experimental Group & 2.0000 & 2.16025 \\
\hline
\end{tabular}


Paper-Exploring Dysphasia Learners' Vocabulary Acquisition through the Cognitive Theory...

Table 2. Statistical data of posttest results

\begin{tabular}{|l|c|c|}
\hline \multicolumn{1}{|c|}{ Pre-test Results } & Mean & Standard Deviation \\
\hline Control Group & 6.8000 & 2.29976 \\
\hline Experimental Group & 10.8000 & 1.22927 \\
\hline
\end{tabular}

Table 3. Statistical data of retention test results

\begin{tabular}{|l|c|c|}
\hline \multicolumn{1}{|c|}{ Pre-test Results } & Mean & Standard Deviation \\
\hline Control Group & 3.4000 & 2.22111 \\
\hline Experimental Group & 9.0000 & 2.16025 \\
\hline
\end{tabular}

Table 4. Statistical data of vocabulary knowledge scale questionnaire results

\begin{tabular}{|l|c|c|}
\hline \multicolumn{1}{|c|}{ Pre-test Results } & Mean & Standard Deviation \\
\hline Control Group & 3.1800 & 1.71085 \\
\hline Experimental Group & 5.4200 & 3.45210 \\
\hline
\end{tabular}

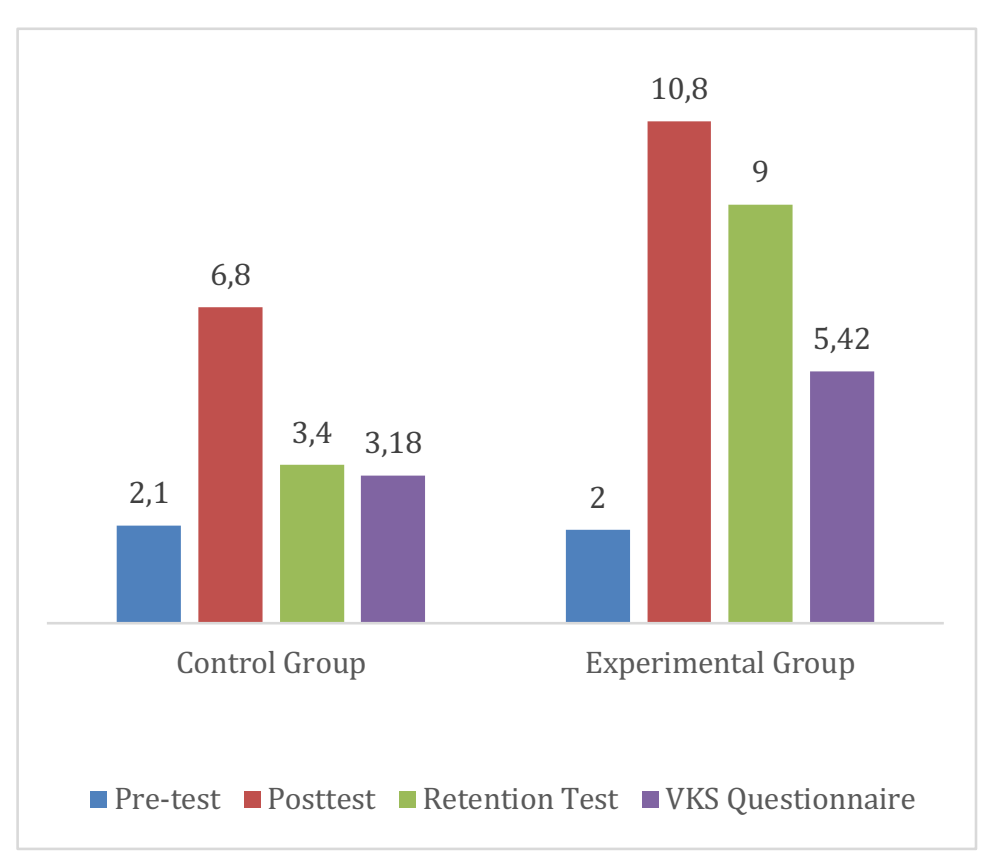

Fig. 1. Mean difference between the control group and the experimental group 


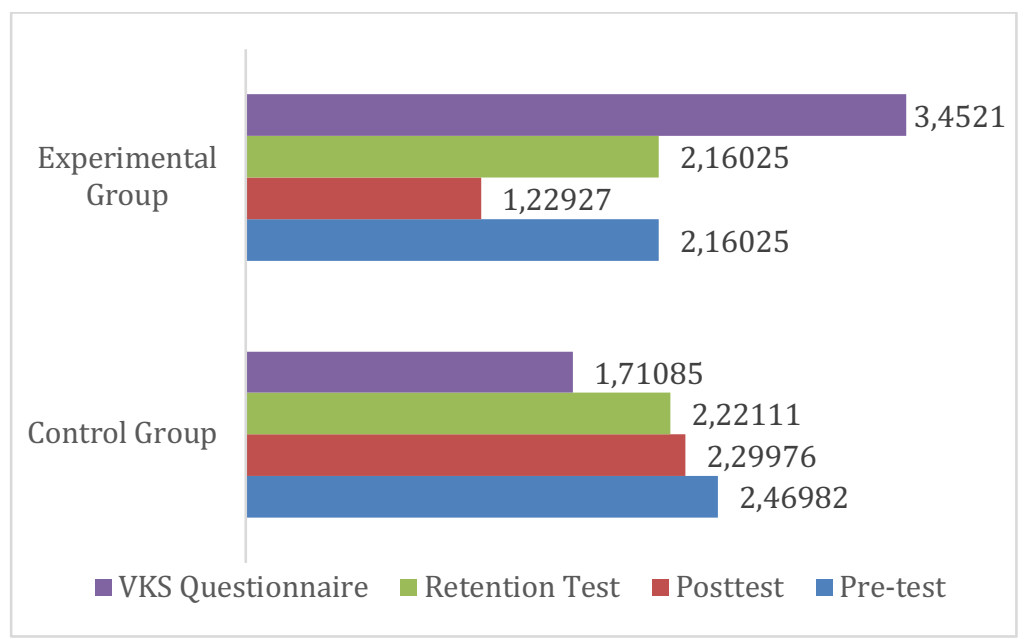

Fig. 2. Standard deviation between the control group and the experimental group

\section{Discussion}

The aim of the study presented in this paper was to explore how multimedia lessons used to enhance vocabulary acquisition for students with dysphasia in learning. The findings are related to the theoretical background and interpreted, pedagogical implications for instructional methods and limitations of the study are presented. From the results of this research, it was evident that dysphasia students performed significantly well in multimedia instructional methods in vocabulary acquisition. The experimental group students found News in level multimedia lesson - Robinson Crusoe for students of English to help improve their English vocabulary. The pre-test and the post-test scores indicate significant differences between the learners who had multimedia instructional lessons integrated into their vocabulary learning and those counter-part group.

As the theoretical framework of this study provides a clear definition of each word to help the students learn better understanding by the cognitive theory of learning instructional approach. Since the theory suggests channelization of information in a way that visual and auditory senses work correctly together, as a result, the learning process becomes more effective. All the dysphasia students exposed to the same treatment of evaluation except the instructional methods. The pre-test consists of 10 closed-ended questions to study their previous knowledge of the language. The statistical data of the pre-test score has no much difference between the control and experimental groups. The control group has a mean value of 2.1000 , and the experimental group has 2.000 , respectively. During the intervention and teaching process, two different instructional methods are followed for both groups. The control group followed only the traditional way of special education training.

On the other hand, the experimental group followed a multimedia instructional method throughout the intervention. The post-test scores revealed significant differ- 
ences between the two groups. The control group's mean score is 6.8000 , whereas the experimental group secured a high rate of difference to 10.8000 in the post-test with another set of closed-ended questions.

The challenging part of teaching special education learners was making them remember the due course's learned things. In order to evaluate and assess the retention of the instructional methods, a retention test was conducted one month after the ten intervention sessions of the intervention. One of the principles of the cognitive theory of multimedia learning is using previous knowledge in learning. This retention test helped the researcher check whether the experimental group students used the principle when they encountered the learning process. The experimental group's mean score on retention showed that dysphasia learners have a lower level of forgetting than the control group. The scores indicated that the multimedia instruction method helped dysphasia students remember the learned words in the teaching-learning process. The retrieval level of learning was higher when compared to the traditional method of instruction. The experimental group gained 9.0000, and the control group scored 3.4000 in the retention test.

Finally, to reaffirm the instructional methods' effectiveness, the Vocabulary Knowledge Scale questionnaire was distributed to know their vocabulary acquisition from the study's entire research process. VKS questionnaire was given to dysphasia participants one week after the retention test. The current study students revealed that multimedia integrating instructional methods motivate them to study and increase their vocabulary acquisition because it was eye-catching and stores the new information in their long-standing memory. The students with dysphasia in the experimental group retain most of the vocabulary of a second language asked in the VKS questionnaire. All the test results scores revealed that News in level lesson - Robinson Crusoe for students of English had highly motivated the vocabulary learning when the lesson was integrated with the multimedia instructional approach.

\section{Conclusion}

Based on the study's findings, it was evident that technology and multimedia can foster and grasp the students' attention with dysphasia in vocabulary learning. So the special education instructors can select a lesson that would improve the learning disabilities students to understand and retain the information in their long-term memory. The convergence of learning analytics and visualization analytics opens up new avenues for defining student core competencies, capabilities, and adaptability. Curriculum designers can make use of News in levels of multimedia lessons in the special education resource room. A comparison of traditional and multimedia instructional approaches revealed the effectiveness and efficiency of the teaching-learning process. Findings from this research can be a base to inform the instructional design of vocabulary intervention programs in special education schools serving children with dysphasia. 


\section{Limitation of the study}

The present study is limited to the vocabulary of dysphasia learners'. The current research constitutes a solution towards limited issues compared to the current issues prevailing in learning disabilities students.

\section{References}

[1] P. Nation, Learning vocabulary in another language. Cambridge: Cambridge University Press, 2001.

[2] D. Pany and J. R. Jenkins, "Learning Word Meanings: A Comparison of Instructional Procedures," Learning Disability Quarterly, vol. 1, no. 2, pp. 21-32, 1978. https://doi.org/10. 2307/1510304

[3] D. P. Bryant, M. Goodwin, B. R. Bryant, and K. Higgins, "Vocabulary Instruction for Students with Learning Disabilities: A Review of the Research," Learning Disability Quarterly, vol. 26, no. 2, pp. 117-128, 2003.https://doi.org/10.2307/1593594

[4] L. Wawryk-Epp, Teaching students with reading difficulties and disabilities: a guide for educators. Regina: Saskatchewan Learning, 2004.

[5] C. A. Hyde, T. F. McLaughlin, and M. Everson, "The Effects of Reading Racetracks on the Sight Word Fluency and Acquisition for Two Elementary Students with Disabilities: A Further Replication and Analysis,” The Open Social Science Journal, vol. 2, no. 1, pp. 5053, 2009. https://doi.org/10.2174/1874945300902010050

[6] M. T. de Jong and A. G. Bus, "Quality of book-reading matters for emergent readers: An experiment with the same book in a regular or electronic format." Journal of Educational Psychology, vol. 94, no. 1, pp. 145-155, 2002. https://doi.org/10.1037/0022-0663.94.1.145

[7] J. Bácsi, "A semantic network dictionary for dysphasia therapy," Acta Cybernetica, vol. 16, no. 4, pp. 601-609, 2004. Retrieved from https://cyber.bibl.uszeged.hu/index.php/actcybern/article/view/3645

[8] O. Dlouhá, "Disfluencies of speech in children with developmental dysphasia," Journal of Fluency Disorders, vol. 25, no. 3, p. 251, 2000. https://doi.org/10.1016/s0094730x(00)80331-9

[9] F. Beauregard, "Practices Adopted by Parents of Children with Dysphasia in Inclusive Primary School," Exceptionality Education International, vol. 21, no. 3, 2011. https://doi.org/10.5206/eei.v21i3.7680

[10] R. Kabooha and T. Elyas, "The Effects of YouTube in Multimedia Instruction for Vocabulary Learning: Perceptions of EFL Students and Teachers," English Language Teaching, vol. 11, no. 2, p. 72, 2018. https://doi.org/10.5539/elt.v11n2p72

[11] Kanellopoulou, Kermanidis, and Giannakoulopoulos, "The Dual-Coding and Multimedia Learning Theories: Film Subtitles as a Vocabulary Teaching Tool," Education Sciences, vol. 9, no. 3, p. 210, 2019. https://doi.org/10.3390/educsci9030210

[12] GAVRONSKAYA, Yulia et al. Virtual Lab Model for Making Online Courses More Inclusive for Students with Special Educational Needs. International Journal of Emerging Technologies in Learning (iJET), [S.1.], v. 16, n. 02, p. pp. 79-94, 2021. https://doi.org/10. 3991/ijet.v16i02.18755

[13] A. B R and R. V, “Advanced Technological Modality to Explore ESL Learners' Vocabulary Knowledge through Social Strategies," Journal of Advanced Research in Dynamical \& Control Systems, vol. 10, no. 10, pp. 250-256, 2018. 
[14] ALMUSHARRAF, Norah; KHAHRO, Shabir. Students Satisfaction with Online Learning Experiences during the COVID-19 Pandemic. International Journal of Emerging Technologies in Learning (iJET), [S.1.], v. 15, n. 21, p. pp. 246-267, 2020. https://doi.org/10. 3991/ijet.v15i21.15647

[15] ZOTOV, Vladimir et al. Engagement of Students in Data Visualization for the Purpose of E-Learning Improvement. International Journal of Emerging Technologies in Learning (iJET), [S.1.], v. 16, n. 02, p. pp. 46-64, 2021. https://doi.org/10.3991/ijet. v16i02.18745

[16] A. K. Jitendra, L. L. Edwards, G. Sacks, and L. A. Jacobson, "What Research Says about Vocabulary Instruction for Students with Learning Disabilities," Exceptional Children, vol. 70, no. 3, pp. 299-322, 2004. https://doi.org/10.1177/001440290407000303

[17] S. R. Vaidya, "Metacognitive learning strategies for students with learning disabilities," Education, vol. 120, no. 1, p. 186, 1999.

[18] J. F. Carlisle, "Free Recall as a Test of Reading Comprehension for Students with Learning Disabilities," Learning Disability Quarterly, vol. 22, no. 1, p. 11, 1999. https://doi.org/10.2307/1511148

[19] [19] B. Ashworth and M. Saunders, "Rehabilitation," Management of Neurological Disorders, pp. 21-35, 1985. https://doi.org/10.1016/B978-0-407-00310-1.50006-3

[20] H. W. Catts, M. S. Bridges, T. D. Little, and J. B. Tomblin, "Reading Achievement Growth in Children With Language Impairments," Journal of Speech, Language, and Hearing Research, vol. 51, no. 6, pp. 1569-1579, 2008. https://doi.org/10.1044/10924388(2008/07-0259)

[21] L. V. M. Hoffman and R. B. Gillam, "Verbal and Spatial Information Processing Constraints in Children With Specific Language Impairment," Journal of Speech, Language, and Hearing Research, vol. 47, no. 1, pp. 114-125, 2004. https://doi.org/10.1044/1092$\underline{4388(2004 / 011)}$

[22] J. W. Montgomery, "Real-time language processing in school-age children with specific language impairment," International Journal of Language \& Communication Disorders, vol. 41, no. 3, pp. 275-291, 2006. https://doi.org/10.1080/13682820500227987

[23] [23] R. E. Mayer, Multimedia Learning, 2nd ed. Cambridge: Cambridge University Press, 2009.

[24] R. E. Mayer and R. Moreno, “Animation as an Aid to Multimedia Learning," Educational Psychology Review, vol. 14, no. 1, pp. 87-99, 2002. https://doi.org/10. 1023/A:1013184611077

[25] B. R. Aravind and V. Rajasekaran, "Using technological modality to learn vocabulary incidentally and intentionally for effective communication," International Journal of Intelligent Enterprise, vol. 7, no. 1/2/3, p. 166, 2020. https://doi.org/10.1504/ijie.2020.104653

\section{Authors}

Aravind B R is pursuing his $\mathrm{PhD}$ in English Language Teaching at the School of Social Sciences and Languages at VIT Chennai, India. He obtained his UG and PG degrees from Loyola College, Chennai and St. Joseph's College of Arts and Science, Cuddalore, respectively. After completing his studies, he taught the English language in his city, where he was the Head of the Department of English for two years. In 2016, he turned to be a full-time researcher in English Language Teaching. His research interest includes vocabulary teaching and learning, web tools for language learning, literary theory and literary criticism. He has published six Scopus Indexed 
papers, four Non-Scopus papers, one Book Chapter and a Book on his research areas. Email: aravind.abur@gmail.com ORCID: 0000-0001-7872-8171.

Dr. V. Rajasekaran is an Assistant Professor Senior at the School of Social Sciences and Languages at VIT Chennai, India. He obtained his Doctorate from Bharathiyar University, Coimbatore, India. His research interest includes applied linguistics, e-learning, comparative literature, modern literature and language learning. He is a research guide for more than six scholars. He has published 25 research articles in Scopus and Non-Scopus journals. He is an active member of many literary and academic bodies. He has authored a list of books on various domains. ORCID: 00000002-1760-4973.

Article submitted 2021-02-19. Resubmitted 2021-03-19. Final acceptance 2021-03-19. Final version published as submitted by the authors. 